\title{
Study of Potential Health Damage Caused by Ultrafine Particles in Megacities Using a Pulmonary Deposition Model
}

\author{
Daniela S. de Almeida, Jorge A. Martins, Lourenço H. B. Vidotto, Leila D. Martins \\ Federal Technological University of Paraná, Londrina, Brazil \\ Email: dannyutfpr@gmail.com
}

Received 10 June 2015; accepted 21 August 2015; published 25 August 2015

\begin{abstract}
The deposition of ultrafine particles, in the human respiratory tract, from four highly impacted megacities across the globe, was evaluated by using a pulmonary deposition model. It was found that, for the locations studied, an average of $62 \%$ of atmospheric particles was retained in the respiratory system. As expected, the model shows that smaller particles penetrate deeper in the airways. In addition, it's shown that children are more susceptible than adults, retaining $8 \%$ more ultrafine particles.
\end{abstract}

\section{Keywords}

Air Pollution, Ultrafine Particles, Pulmonary Deposition

\section{Introduction}

The exposure to air pollution is largely determined by the pollutants concentration in ambient air, around which people spend their time, and also by the amount of time under exposure. The most consistent explanation to the adverse effects of air pollutants is that the contact of said pollutants in high concentration with the respiratory epithelium causes the formation of oxygen and nitrogen free radicals, inducing an oxidative stress in the respiratory airways [1]. Due to the extensive contact area between the respiratory system and the environment, air quality has a direct influence over respiratory human health.

Fine and mainly ultrafine particles (less than $100 \mathrm{~nm}$ of aerodynamic diameter) have been shown to be potential health-damaging pollutants. Several evidence sources have demonstrated that respirable particles lead to harmful effects in the lungs and other organs [2]-[5].

Developed and developing countries have made great efforts to improve air quality by means of adopting certain public policies, such as creating standards for atmospheric pollutants emission, continuous air quality monitoring in urban areas and industrial sites, or adopting cleaner fuels, like natural gas [6]. At the same time, accompanying the development of countries, there is a phenomenon of migration from rural to urban areas that increases atmospheric emission, due mainly to vehicular traffic.

These factors have been causing long-term changes in air quality at urban areas, especially in the 1990s when

How to cite this paper: de Almeida, D.S., Martins, J.A., Vidotto, L.H.B. and Martins, L.D. (2015) Study of Potential Health Damage Caused by Ultrafine Particles in Megacities Using a Pulmonary Deposition Model. Journal of Geoscience and Environment Protection, 3, 67-71. http://dx.doi.org/10.4236/gep.2015.36011 
most policies on clean air were reinforced by the Kyoto Protocol [7]. Additionally, plenty of data regarding air quality is available online.

Based on that, the aim of this work was to use ultrafine particles data from four megacities and apply it to a pulmonary deposition model, in order to estimate the amount of particles present in the environment that can be deposited in the human respiratory tract.

\section{Methodology}

\subsection{Characterization of the Study Location}

A theoretic study was made to help choose the ultrafine particles data from four cities and apply it to the model. Information about the average mass concentration and average particle diameter for each site were obtained for Los Angeles, Mexico City, Lucknow and São Paulo [8]-[11], respectively. The data is shown in Table 1, along with the year of measurement.

The Mexico City's metropolitan area is an example of extreme growth and severe environmental pollution. It accommodates 20 million people, more than 40 thousand factories and 4 million vehicles. The exposure becomes considerably different when it comes to the concentrations of pollution sources, such as industrial and mobile sources [12].

Los Angeles, in 2002, had an average population in its metropolitan region of 15 million people and about 10 million vehicles [8]. It's the second most populous city in the U.S. and it's an international center for business, trading, culture, technology and education.

Lucknow, India, is the $10^{\text {th }}$ most polluted city in the world, according to a WHO (World Health Organization) report in 2014 [13]. Its population is around 3 million [14] and some of its main problems are the population explosion and extreme poverty, aggravated by the frequent mixture of politics and religion in the country.

The city of São Paulo has a population of about 11 million [15] and a vehicle fleet of more than 7 million [16]. vehicles older than 10 years represent more than $50 \%$ of the fleet and are responsible for most of the emission [17].

\subsection{Pulmonary Deposition Model}

In order to run the numerical simulation of pulmonary deposition for the gathered data, a model named MPPD (Multiple Path Particle Dosimetry Model) was used [18] [19]. This model calculates deposition and removal of particles in the respiratory tract for particle sizes ranging from $0.01 \mu \mathrm{m}$ (ultrafine) to $10 \mu \mathrm{m}$ (coarse). Some species, pulmonary and particulate parameters are necessary to generate the results, for example, graphs showing the retained particulate fraction in different regions of the respiratory tract.

Humans were selected for the species parameters, with Yeh/Schum Symmetric geometry, nasal respiratory route. The particle density adopted was $1 \mathrm{~g} \cdot \mathrm{cm}^{-3}$, considered as default by the model. These choices of model defaults must be considered when analyzing the results.

Information about the respiratory tract was retrieved from Winter-Sorkina and Cassee [20]. For this work, two age groups were chosen: 3-year-old children and adults (individuals of age 21 or older). The data displayed in Table 2 represents mean values. The increase in the individual's activities has an impact on these parameters.

\section{Results and Discussion}

The graphs in Figure 1 show fractions of accumulated particles in three regions from the respiratory tract. HEAD represents the upper respiratory tract, TB is the tracheobronchial section and $\mathrm{P}$ is the pulmonary section.

Table 1. Model data used for particles from different sites.

\begin{tabular}{cccc}
\hline Year & City & Average Mass Concentration $\left(\mu \mathrm{g} \cdot \mathrm{m}^{-3}\right)$ & Particle Diameter Range $(\mu \mathrm{m})$ \\
\hline 2002 & Los Angeles (USA) & $0.006-0.22$ \\
2004 & Mexico City (MEX) & 47.58 & $0.003-0.040$ \\
2011 & Lucknow (IND) & 6.08 & 0.05 \\
2013 & São Paulo (BRA) & 8.31 & 0.048 \\
\hline
\end{tabular}

${ }^{1}$ The data for Los Angeles represents a distance of 30 meters from the emission source [8]; ${ }^{2}$ The data for São Paulo represents measurements at the Jânio Quadros tunnel [11]; ${ }^{3}$ For Lucknow, the values of particle concentration and diameter are not averages. 
The major deposition mechanism for ultrafine particles inside the respiratory tract is the Brownian diffusion [21]. Following this premise, the expected result from the MPPD model is that as the particle size decreases, the inhaled portion in each region would increase. However, there are different deposition probabilities due to the particles variable size and chemical composition. An inverse behavior to the expected by the model was observed in Los Angeles, as the graph in Figure 1 shows. The remaining graphs show an increase of the retained fraction, from the upper to the lower tract area, HEAD and TB, respectively.

Table 2. Model data used as respiratory parameters obtained from Winter-Sorkina [20].

\begin{tabular}{|c|c|c|c|c|}
\hline $\begin{array}{c}\text { Age } \\
\text { (years) }\end{array}$ & Functional Residual Capacity (mL) & Upper Respiratory Tract (mL) & $\begin{array}{c}\text { Breathing } \\
\text { Frequency }\left(\mathrm{min}^{-1}\right)\end{array}$ & $\begin{array}{l}\text { Tidal Volume } \\
\text { (mL) }\end{array}$ \\
\hline 3 & $500^{1}$ & 9.47 & 24 & 121.3 \\
\hline 21 & 1854.54 & 42.27 & 14 & 477.2 \\
\hline
\end{tabular}

${ }^{1}$ The reference value is $95.43 \mathrm{~mL}$; however, the minimum accepted value by the software is $500 \mathrm{~mL}$.
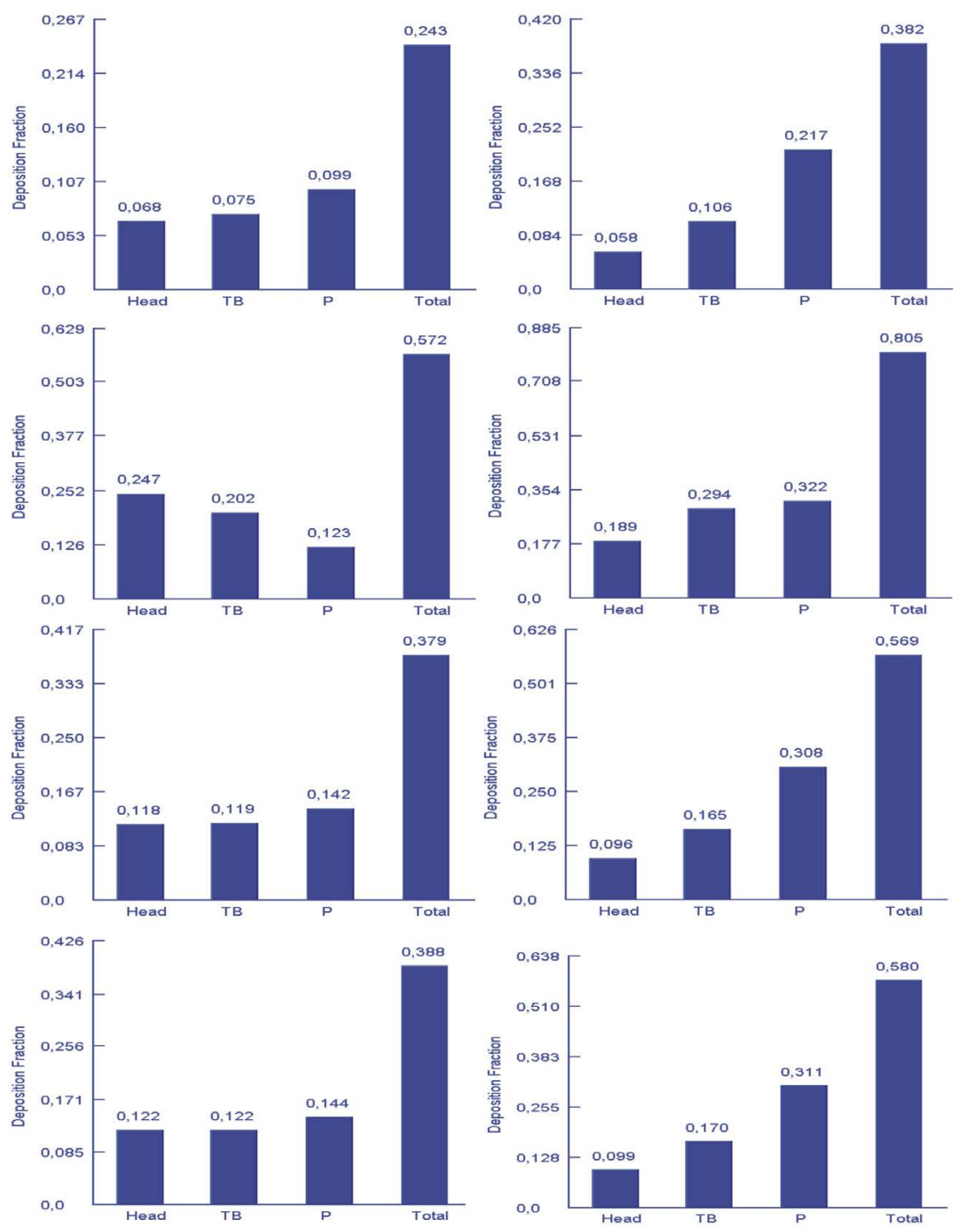

Figure 1. Graphs representing the ultrafine particles fractions deposited in the three regions of the respiratory tract. The right column refers to children results and the left to adults. The first, second, third and fourth rows represent, respectively, the cities of Lucknow, Los Angeles, Mexico City and São Paulo. HEAD = Upper respiratory tract; TB = tracheobronchial section; $\mathrm{P}=$ Pulmonary section. 
Still regarding Los Angeles, a greater retained fraction was observed (total) compared to the other cities, which may be explained by the high average concentration and particles with lower average diameter. The data from Zhu et al. [8] was obtained from an experiment that measured particles at a main city highway, with an average flow of 13,900 vehicles an hour (at the time of the experiment). That justifies the high concentrations of atmospheric particles.

For Mexico City, the data used from Dunn [9] was obtained in a mountainous region around the city. The maximum particle concentrations found were lower than the expected for an urban region; however, it's likely that a dilution has occurred, significantly reducing the initial aerosol concentration emitted in the city.

In São Paulo, the data collected by Brito et al. [11] was obtained from measurements in the Jânio Quadros tunnel, with a flow of 1806 vehicles an hour (during the experiments). It is forbidden for heavy-duty vehicles to enter in this tunnel and the emission comes mainly from gasoline and ethanol powered vehicles. The total inhaled fraction is about 65\% as showed in Figure 1.

For Lucknow, the results were similar to those of São Paulo; it can be observed that, despite the different particles concentrations, the diameters were the same. Maybe the MPPD model depends more on parameters like particle diameter to estimate their behavior inside the respiratory tract.

With respect to the two age groups studied, there was a difference of $8 \%$ between children and adults, with children retaining greater portions of fine particulate, according to the model. This behavior was obtained with all the cities in this study.

Except for Los Angeles, the deposited fraction of total particles, in average, was 65\% for children and 59\% for adults.

Epidemiologic studies indicate that the smaller the particles in contact with the respiratory system, the higher can be the damage they cause, since ultrafine particles are able to penetrate the blood flow. Acute exposure to this atmospheric pollutant raises the risk of cardiovascular diseases due to chronic pulmonary exposure [19].

\section{Conclusions}

Considering that the data used is not from personal exposure, it can be said that, according to the MPPD model, an average of $62 \%$ of atmospheric particles in the study locations is retained in the human respiratory system. Further, the particle intake in children could be $8 \%$ higher than adults indicating they are more susceptible.

Finally, the modeling results show that the most significant health effects appear with lower particles sizes. Therefore, more public policies are needed that address the public control of source emissions that directly or indirectly increase the particles concentrations in the atmosphere, mainly in developing countries.

\section{Acknowledgements}

This work received funding support from CNPq (National Counsel of Technological and Scientific Development, process 404104/2013-4), CAPES (Coordination for the Improvement of Higher Education Personnel) and Araucária Foundation.

\section{References}

[1] Arbex, M.A., de Paula Santos, U., Martins, L. C., Saldiva, P.H.N., Pereira, L.A.A. and Braga, A.L.F. (2012) A Poluição do Ar e o Sistema Respiratório. Jornal Brasileiro de Pneumologia, 38, 643-655. http://dx.doi.org/10.1590/S1806-37132012000500015

[2] World Health Organization (2006) Air Quality Guidelines: Global Uptade 2005.

[3] Obersörster, G., Obersörster, E. and Obersörster, J. (2005) Nanotoxicology: An Emerging Discipline Evolving from Studies of Ultrafine Particles. Environmental Health Perspectives, 113, 823-839. http://dx.doi.org/10.1289/ehp.7339

[4] Sioutas, C., Delfino, R.J. and Singh, M. (2005) Exposure Assessment for Atmospheric Ultrafine Particles (UFPs) and Implications in Epidemiologic Research. Environmental Health Perspectives, 113, 947-955. http://dx.doi.org/10.1289/ehp.7939

[5] Asgharian, B. and Price, O.T. (2007) Deposition of Ultrafine (NANO) Particles in the Human Lung. Inhalation Toxicology, 19, 1045-1054. http://dx.doi.org/10.1080/08958370701626501

[6] Baldasano, J.M., Valera, E. and Jimenéz, P. (2002) Air Quality Data from Large Cities. The Science of the Total Environment. 
[7] Moreira, H.M. and Giometti, A.B.R. (2008) Protocolo de Quioto e as possibilidades de inserção do Brasil no Mecanismo de Desenvolvimento limpo por meio de projetos em energia limpa.Contexto Internacional, 30. http://dx.doi.org/10.1590/S0102-85292008000100001

[8] Zhu, Y., Hinds, W.C., Kim, S. and Sioutas, C. (2002) Concentration and Size Distribution of Ultrafine Particles near a Major Hightway. Journal of the Air and Waste Management Association, 52, 1032-1042. http://dx.doi.org/10.1080/10473289.2002.10470842

[9] Matthew J. Dunn, M.J., Jiménez, J.L., Baumgardner, D., Castro, T., McMurry, P.H. and Smith, J.N. (2004) Measurements of Mexico City Nanoparticle Size Distributions: Observations of New Particle Formation and Growth. Geophysical Research Letters, 31, L10102.

[10] Verma, M.K., Chauhan, L.K.L., Sultana, S. and Kumar, S. (2011) The Traffic Linked Urban Ambientair Superfine and Ultrafine PM1 Mass Concentration, Contents of Pro-Oxidant Chemicals, and Their Seasonal Drifts in Lucknow, India. Atmospheric Pollution Research, 5.

[11] Brito, J., Rizzo, L.V., Herckes, P., Vasconcellos, P.C., Caume, S.E.S., Fornaro, A., Ynoue, R.Y., Artaxo, P. andAndrade, M.F. (2013) Physical-Chemical Characterization of the Particulate Matter inside Two Road Tunnels in the São Paulo Metropolitan Area. Atmospheric Chemistry and Physics, 13, 12199-12213. http://dx.doi.org/10.1080/10473289.2002.10470842

[12] Calderón-Garcidueñas, L. and Torres-Jardón, R. (2012) Air Pollution, Socioeconomic Status, and Children’s Cognition in Megacities: The Mexico City Scenario. Frontiers in Psychology, 3, 217.

[13] Whiting, N. (2014) Air Pollution: 10 Countries with the World's Dirtiest air. ABC News. http://www.abc.net.au/news/2014-05-08/10-countries-with-the-worlds-dirtiest-air/5438872

[14] CENSUS (2011) Lucknow City Census 2011 Data. http://www.census2011.co.in/census/city/127-lucknow.html

[15] IBGE-Instituto Brasileiro de Geografia e Estatística (2014) Sala de imprensa: Estimativas Populacionais dos Municípios.

[16] DETRAN—Departamento Estadual De Trânsito De São Paulo (2013) Frota de Veículos.

[17] Andrade, M.F., Miranda, R.M., Fornaro, A., Kerr, A., Oyama, B., De Andrade, P.A. and Saldiva., P.H.N. (2010) Vehicle Emissions and PM2.5 Mass Concentraton in Six Brazilian Cities. Air Quality, Atmosphere \& Health, 13, 7988.

[18] Asgharian, B., Hofmann, W. and Bergmann, R. (2001) Particle Deposition in a Multiple-Path Model of the Human Lung. Aerosol Science and Technology, 34, 332-339. http://dx.doi.org/10.1080/02786820119122

[19] Martins, L.D., Martins, J.A., Freitas, E.D., Mazzaroli, C.R., Gonçalves, L.T., Ynoue, R.Y., Hallak, R., Albuquerque, T.T.A., de Fatima Andrade, M. (2010) Potential Health Impact of Ultrafine Particles under Clean and Polluted Urban Atmospheric Conditions: A Model-Based Study. Air Quality Atmospheric Health, 3, 29-39. http://dx.doi.org/10.1007/s11869-009-0048-9

[20] De Winter-Sorkina, R. and Cassee, F.R. (2002) From Concentration to Dose: Factors Influencing Airborne Particulate Matter Deposition in Humans and Rats. National Institute for Public Health and the Environment, RIVM, Projeto 650010, the Netherlands.

[21] Scheuch, G., Kohlhaeufl, M.J., Brand, P. and Siekmeier, R. (2006) Clinical Perspectives on Pulmonary Systemic and Macromolecular Delivery. Advanced Drug Delivery Reviews, 58, 996-1008.

http://dx.doi.org/10.1016/j.addr.2006.07.009 